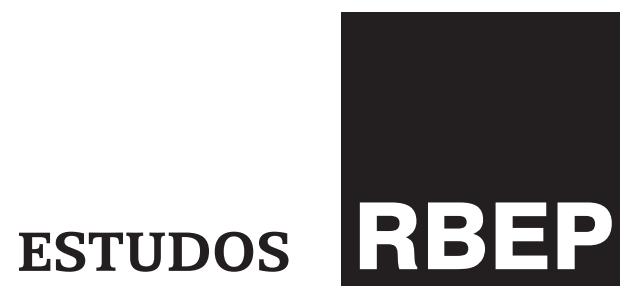

\title{
O ensino de Estatística na educação básica com foco na interdisciplinaridade: um estudo comparativo
}

Adriana Pagan

Sandra Magina

\section{Resumo}

Compara e discute os ganhos de aprendizagem de três grupos de alunos da $1^{\mathrm{a}}$ série do ensino médio que tiveram contato com conceitos elementares de estatística, a partir das aulas de Matemática (GM), Geografia (GG) e Matemática aplicada de forma interdisciplinar (GI). O estudo, realizado em uma escola pública de São Paulo, teve três etapas: duas diagnósticas (pré e pós-testes) e uma de intervenção de ensino (diferentes em cada grupo e realizadas por professores distintos). Os aportes teóricos foram o Registro de Representação (Duval, 1995) e a classificação da leitura de dados em tabelas (Wainer, 1992) e gráficos (Curcio, 1989). Os resultados mostraram que os três grupos tiveram ganhos, porém os alunos do GI apresentaram desempenho significativamente superior ao dos demais grupos, indicando que o ensino de estatística pautado na interdisciplinaridade foi o mais eficaz para a aquisição de conhecimento dos elementos estatísticos.

Palavras-chave: ensino médio; interdisciplinaridade; intervenção de ensino; construção e interpretação de gráficos e tabelas. 


\section{Abstract \\ Statistics education in basic education focused on interdisciplinarity: a comparative study}

The present study compares and discusses the learning gains among three groups of students from the $9^{\text {th }}$ grade who had contact with some statistics elementary concepts through Math, Geography and applied Math classes. It was carried out in a public school in São Paulo and had three phases: two diagnostic phases (pre and post tests) and a learning intervention (different in each group and with distinct teachers). The theoretical approach was the registrations representation (Duval,1995), the data reading (Wainer,1992) and graphics (Curcio,1989). The results showed gains in the three groups, however, the applied math students had a superior gain in comparison to the other groups what is an indicator that statistics education based on interdisciplinarity is more effective to the acquisition of statistical elements.

Keywords: high school; interdisciplinarity; learning intervention; graphics and tables interpretation.

\section{Introdução}

É inegável a importância que os gráficos estatísticos assumiram nas últimas décadas, nas mais variadas áreas do conhecimento. Quando presentes em livros, revistas e jornais, os gráficos facilitam o entendimento da informação para a maioria das pessoas.

Além de serem utilizados como meio rápido e fácil de comunicação, os gráficos estatísticos também são úteis na busca de padrões de comportamento e relações entre variáveis, na descoberta de novos fenômenos, na aceitação ou rejeição de hipóteses, etc.

Duval (1995) enfatiza que o domínio da compreensão e análise de informações apresentadas em gráficos e tabelas pressupõe o também domínio de construção desses dois tipos de representação, pois isso implica o desenvolvimento da capacidade de interpretação. No entanto, na maioria das vezes, o cidadão comum não tem esse conhecimento da construção, podendo ser facilmente enganado ao observar um gráfico não apropriado à situação ou mesmo construído de maneira incorreta, o que lhe passará uma imagem errônea da informação.

A partir dessa preocupação, decidimos investigar como se dá o ensino de Estatística aos alunos da educação básica, pois a escola tem responsabilidade na formação desses cidadãos, e ela é, por excelência, o lugar para a aprendizagem de tal conteúdo. 
Observamos que a inserção do ensino de Estatística na educação básica brasileira é algo recente, já que, em nível estadual, ela só passou a integrar, ainda que de maneira tímida, as propostas curriculares do ensino do Estado de São Paulo a partir da década de 1980. Em nível federal, a Estatística passou a fazer parte do currículo ainda mais tarde, apenas em 1997, com o surgimento dos Parâmetros Curriculares Nacionais (PCN).

Para a disciplina de Matemática, os PCN (Brasil, 1998) agrupam os conteúdos em quatro grandes blocos, sendo um deles intitulado de Tratamento da Informação (TI). Este engloba os conteúdos conceituais e procedimentais de Estatística, Análise Combinatória e Probabilidade, iniciando já no $1^{\circ}$ ciclo ( $1^{\mathrm{a}}$ e $2^{\mathrm{a}}$ séries) do ensino fundamental e se fazendo presente em todas as séries subsequentes, até o último ano do ensino médio. Tal presença é uma demonstração da preocupação do sistema educacional brasileiro com o letramento estatístico de seu cidadão.

Segundo Gal (2002), ser letrado estatisticamente é ter conhecimentos mínimos de conceitos e ideias estatísticas e saber utilizá-los na solução de problemas enfrentados no seu cotidiano.

Diversos autores que estudam a área de Educação Estatística discutem a importância desse tema no ensino básico. Entre eles, Lopes (2004a) argumenta sobre a importância de o aluno adquirir conhecimentos para interpretar e comparar dados e, ainda, tirar conclusões:

\begin{abstract}
No mundo das informações, no qual estamos inseridos, torna-se cada vez mais "precoce" o acesso do cidadão a questões sociais e econômicas em que tabelas e gráficos sintetizam levantamentos; índices são comparados e analisados para defender idéias. Dessa forma, faz-se necessário que a escola proporcione ao estudante, desde o ensino fundamental, a formação de conceitos que o auxiliem no exercício de sua cidadania. (Lopes, 2004a, p. 2-3).
\end{abstract}

No que diz respeito ao ensino fundamental e ao ensino médio, os conceitos e procedimentos da Estatística estão relacionados aos da Matemática. Eles, contudo, diferem quanto ao objetivo, pois enquanto os conceitos estatísticos têm o foco em descrever, organizar, resumir e comunicar dados coletados sobre fenômenos das diversas ciências, os da Matemática centram-se no desenvolvimento do raciocínio lógico, por meio dos cálculos necessários para a interpretação e análise dos dados.

Por essa razão, entendemos que quase todas as ciências usam conceitos e procedimentos da Estatística, ou seja, os profissionais de outras ciências aprendem a utilizá-los, muitas vezes, sem ter a preocupação com os aspectos matemáticos ou conceituais subjacentes a eles.

Por outro lado, a partir de depoimentos de inúmeros professores veteranos e de recém-formados, notamos que os cursos de Licenciatura em Matemática costumam trabalhar esses conteúdos estatísticos apenas do ponto de vista de suas disciplinas. Embora reconheçamos que nossa fonte foi empírica e sem base científica, não é sem fundamento, pois costumamos ouvir de dezenas de professores de Matemática que atuam na educação básica que suas licenciaturas contemplaram a disciplina de 
Estatística como um ensino em si mesmo. Assim é que, aparentemente, os licenciados em Matemática possuem o arcabouço matemático subjacente aos conteúdos estatísticos, mas não têm uma compreensão de como fazer a interdisciplinaridade utilizando a Estatística a seu favor.

Na perspectiva escolar, para os autores dos Parâmetros Curriculares Nacionais do Ensino Médio - PCNEM (Brasil, 1999), a interdisciplinaridade não tem a pretensão de criar novas disciplinas, mas utilizar os conhecimentos de várias delas para resolver problemas ou compreender fenômenos sob diferentes pontos de vista. Dessa forma, assume a função instrumental, recorrendo a um saber diretamente útil e utilizável para responder questões e problemas sociais. Ela é vista, também, como sendo mais um recurso para ampliar as inúmeras possibilidades de interação entre disciplinas.

As habilidades para descrever e analisar dados, realizar inferências e fazer predições com base em uma amostra da população, aplicadas a fenômenos naturais e do cotidiano, são funções da Matemática ao estudarmos a Estatística. Segundo os autores dos PCNEM (Brasil, 1999, p. 257), as técnicas e raciocínios que são instrumentos tanto das Ciências da Natureza como das Ciências Humanas mostram como é "importante uma cuidadosa abordagem dos conteúdos de contagem, estatística e probabilidade no ensino médio, ampliando a interface entre o aprendizado da Matemática e das demais ciências e áreas".

Uma nova proposta curricular para o Estado de São Paulo entrou em vigor em 2008 e restringe o ensino dos conteúdos de Estatística à disciplina de Matemática, fazendo parte do bloco Tratamento da Informação nos quatro anos que compõem o $1^{\circ}$ ciclo do ensino fundamental. Já nas $5^{\mathrm{a}}$ e $6^{\mathrm{a}}$ séries deste nível de ensino e na $3^{a}$ série do ensino médio, esse conteúdo aparece com a denominação Estatística. Nos outros anos, encontra-se diluído nas disciplinas usuárias desse conteúdo, tais como Geografia, que compõe a área das Ciências Humanas, e também Física, Química e Biologia, disciplinas que formam a área das Ciências da Natureza.

Podemos inferir que existe um pressuposto subjacente nessa diretriz, qual seja, o de que a Estatística é para ser trabalhada interdisciplinarmente. Dessa forma, caberá aos professores, dentro de suas disciplinas, ensinar, sempre que pertinente, as noções de Estatística como ferramentas para a aprendizagem de seus conteúdos.

Nessa direção, Lopes (2004b) enfatiza que a Estatística não está restrita à Matemática, mas se relaciona com assuntos de diversas disciplinas, reforçando seu caráter interdisciplinar. Ainda, segundo essa mesma autora, a escola preparará os alunos para a realidade, possibilitando-lhes fazer conjecturas, formular hipóteses e estabelecer relações, cujos processos são necessários para a resolução de problemas, pois não há sentido trabalhar atividades de ensino que envolvam conceitos estatísticos isolados de uma problemática.

Klein (2007, p. 117), comungando de ideias similares, argumenta que existem grandes motivos para que a educação, nas últimas décadas, esteja voltada à interdisciplinaridade. 
O peso da pressão dos problemas sociais, tecnológicos e econômicos tem resultado em uma orientação pragmática em todas as matérias escolares, disciplinas, profissões, na educação geral e nos programas de estudo interdisciplinar. A justificativa mais comum é o argumento do "mundo real". A vida, segundo esse argumento, é "naturalmente" interdisciplinar, portanto, a educação interdisciplinar reflete o "mundo real" de maneira mais eficiente do que a instrução tradicional.

Esse autor alega que, ao trabalhar de forma interdisciplinar, os alunos se sentem mais motivados e mais capazes de lidar com questões e problemas complexos. Eles aprendem a ver conexões entre as disciplinas, mostram mais criatividade e atenção e, até mesmo, uma melhora na assimilação de conteúdos.

Batanero (2001, p. 7), outra autora de referência na área, salienta a necessidade de se ter cuidado ao delegar o ensinamento da Estatística para professores de outras ciências (Ciências Sociais, Biologia, Geografia), pois "pode ocasionar conflitos quando as definições ou propriedades apresentadas dos conceitos não coincidem com as contrapartidas na aula de Matemática". Ela considera inevitável o uso de conhecimentos estatísticos em diversas disciplinas, mas sua preocupação está com a formação dos professores que irão ministrar esse assunto.

\section{Pressupostos teóricos}

O suporte teórico que subsidiou nosso estudo adveio da Teoria de Registros de Representação Semiótica, a qual diz respeito à mudança de registro, segundo o olhar de Duval (1995, 2003). Recorremos ainda às classificações propostas por Curcio (1989), para gráfico, e por Wainer (1992), para tabela, quanto aos níveis de leitura de dados realizados por estudantes nesses dois tipos de representação.

O estudo da Matemática constitui um campo privilegiado para a análise das atividades cognitivas, tais como a conceitualização, o raciocínio, a resolução de problemas e a compreensão de textos. Para que a análise ocorra, faz-se necessário o uso de diferentes representações e de expressões, além da linguagem natural ou das imagens (Duval, 1995).

Duval (2003, p. 14) sustenta que a compreensão da atividade matemática "está na mobilização simultânea de ao menos dois registros de representação semiótica ao mesmo tempo, ou na possibilidade de trocas em todo momento de registro de representação".

Segundo a Teoria dos Registros de Representação, entendemos que, ao deparar-se com uma atividade estatística na qual os dados estão explicitados mediante uma tabela, o aluno terá uma compreensão satisfatória se for capaz de mobilizar esses dados representando-os por meio de um gráfico, ou, se apresentados em um gráfico, representando-os por meio de uma tabela. 
Duval (1995) refere que, do ponto de vista cognitivo, é a atividade de conversão que aparece como a atividade de transformação representacional fundamental, aquela que conduz aos mecanismos subjacentes à compreensão. Saber articular registros constitui uma condição de acesso ao entendimento matemático.

Assim é que, se solicitamos aos alunos que façam mudança de registro ou mobilizem simultaneamente dois registros e eles não conseguem fazê-lo, podemos observar os seus fracassos ou bloqueios. Acreditamos que isso ocorre quando o estudante se mostra capaz de manusear os objetos (matemáticos) por meio de um único registro, não reconhecendo o mesmo objeto matemático em duas representações diferentes. Do ponto de vista do processo de aprendizagem desse estudante, tal limitação trará como consequência outra limitação, qual seja a incapacidade em utilizar os conhecimentos já adquiridos para obter novos conhecimentos matemáticos, bem como a capacidade de compreensão e da própria aprendizagem.

Com vista a oferecer uma visão global dos dados apresentados, precisamos, primeiramente, agrupá-los e identificar suas variáveis, para que possamos montar uma tabela para representá-los.

Novaes e Coutinho (2008) consideram tabela como uma forma de organizar os dados coletados para uma pesquisa, em que cada linha corresponde a um sujeito da pesquisa e cada coluna, a uma característica observada.

Quanto aos dados contidos em uma tabela, podemos classificar o nível de leitura que estamos realizando. Assim, verificamos qual o conhecimento a respeito da leitura de dados obtidos por meio de uma tabela que nossos alunos têm adquirido ao longo dos anos escolares.

Utilizaremos a classificação proposta por Wainer (1992) para medir o nível de leitura de dados constantes de tabelas em que um indivíduo se encontra. São eles:

Nível básico - nível em que as questões somente extraem da tabela os dados que estão explícitos.

Nível intermediário - é o nível em que as questões exigem a interpolação ou a percepção da relação existente entre os dados de uma tabela.

Nível avançado - é o nível em que as questões abordam um maior entendimento das estruturas dos dados em sua totalidade, comparando tendências, analisando questões implícitas e privilegiando a visão global da tabela.

Wainer (1992) considera que, do ponto de vista da construção, é comum encontrar tabelas "pobres" que contemplam no máximo cinco questões e, geralmente, só exploram o nível básico. O autor ainda argumenta que o nível de dificuldade exigido em questões criadas com base em uma tabela se refere, no geral, à manipulação algébrica dos valores constantes em lugar do aprofundamento do nível de inferência. 
Em relação aos gráficos, eles também têm uma importância muito grande nos diversos meios de comunicação, pois são tidos como apresentação de dados de fácil leitura e visualmente agradáveis. Os gráficos têm a característica de poder representar grande quantidade de informações em pouco espaço. Entre outras qualidades, podemos ainda dizer que são poderosos instrumentos a serviço das informações.

Ao pensar na leitura de gráficos e na grande presença destes nos livros didáticos, concluímos que o ensino desse tipo de representação, quanto à sua construção e leitura, exerce um papel importante na instrução formal do aluno.

Para amparar a compreensão da leitura de gráficos, buscamos em Curcio (1989) os níveis que considera importantes. São eles:

Leitura dos dados - leitura de dados explícitos, exigindo um nível cognitivo de compreensão muito baixo.

Leitura entre os dados - exige a habilidade de comparar quantidades e inclui a interpretação e a integração dos dados no gráfico. Requer um grau de inferência lógica necessária para que haja uma resposta coerente à questão.

Leitura além dos dados - requer uma predição ou inferência com base nos dados, informação que não é explícita ou implicitamente apresentada no gráfico.

Com essas ideias teóricas em mente, construímos nosso estudo, o qual se encontra descrito na seção a seguir.

\section{O estudo}

Nosso estudo teve como objetivo comparar os ganhos de aprendizagem entre três grupos distintos de alunos da $1^{\mathrm{a}}$ série do ensino médio que tiveram contato com conceitos elementares da Estatística (construção de gráficos e tabelas e leitura e interpretação de dados) por meio das aulas de Geografia (GG), de Matemática (GM) e de aulas aplicadas de forma interdisciplinar (GI). Para efeito de controle dessas aulas, ficaram previamente acertados os conteúdos estatísticos que todos os três professores trabalhariam em suas aulas e o número de aulas dedicadas a cada grupo.

Ao realizarmos esse estudo com as três turmas, queríamos comparar o conhecimento adquirido pelos alunos, quanto à aprendizagem de noções da Estatística, a partir das intervenções de ensino de um professor da disciplina de Geografia e de dois professores da disciplina de Matemática. Um desses professores de Matemática tratou o assunto de forma interdisciplinar, enquanto o outro não.

Dessa forma, o estudo utilizou três grupos de 35 alunos cada, que cursam a $1^{\mathrm{a}}$ série do ensino médio regular de uma escola da rede pública do Estado de São Paulo e cujas idades estão entre 15 e 17 anos. 
Dividimos nosso estudo em três etapas: a primeira constou de um questionário (pré-teste), aplicado nos três grupos, contendo questões abertas no que diz respeito à construção de tabelas e gráficos e à leitura e interpretação de dados apresentados nesses dois tipos de representação. O objetivo dessa etapa era verificar o desempenho dos grupos no que se refere ao conhecimento prévio de Estatística, uma vez que, supostamente, essas noções já foram trabalhadas no ensino fundamental. $\mathrm{Na}$ segunda etapa, iniciada 15 dias após a primeira, ocorreu a intervenção de ensino em cada um dos grupos - os professores ministraram noções básicas de Estatística em seis encontros de duas horas/aula cada durante seis semanas. Por fim, na terceira etapa, realizada 15 dias após o término da segunda, reaplicamos o questionário (pós-teste), idêntico ao da primeira etapa, porém com a ordem das questões trocada, nos três grupos. O objetivo dessa última etapa foi avaliar, em termos de aprendizagem, as três intervenções de ensino.

Para atender aos objetivos deste artigo, analisaremos apenas os resultados apresentados pelos alunos dos três grupos em quatro das sete questões dos instrumentos diagnósticos (pré e pós-testes), as quais envolveram oito itens. As questões 1 e 6 disseram respeito à construção (mudança de registro de tabela para gráfico e de gráfico para tabela, respectivamente); os itens $2 \mathrm{~A}$ e $5 \mathrm{~A}$ envolveram a leitura de dados globais (comparação); os itens $2 \mathrm{~B}$ e $5 \mathrm{~B}$ trataram da leitura de dados globais (variação); por fim, os itens $2 \mathrm{C}$ e 5C abrangeram a leitura de dados pontuais em tabela e gráfico, respectivamente.

\section{Análise dos resultados}

Iniciamos a análise apresentando um panorama geral dos três grupos quanto aos seus desempenhos nos pré e pós-testes.

Para maior confiabilidade dos resultados, realizamos vários testes estatísticos com o intuito de comparar os desempenhos apresentados pelos grupos nos dois instrumentos diagnósticos.

A Figura 1 mostra que os três grupos partiram de patamares similares de desempenho. O resultado do teste $\mathrm{F}$ (Anova one-way) ${ }^{1}$ apontou que não houve diferença estatisticamente significativa nos desempenhos dos três grupos em relação ao pré-teste $[F(2,102)=2,880 ; p=0,061]^{2}$, e chegaram a patamares superiores no pós-teste.

Quanto ao crescimento dos grupos do pré para o pós-teste, o teste t de Student apontou que todos apresentaram crescimento em seus desempenhos, indicando ainda que o maior desses crescimentos aconteceu no GI [t (35) = -6,070; p = 0,000]. Por fim, ao compararmos os grupos no pós-teste, o GI apresentou desempenho estatisticamente superior aos dos outros dois grupos $[\mathrm{F}(2,102=11,007 ; \mathrm{p}=0,000]$. Esse resultado indica que a intervenção de ensino pautada nos moldes da interdisciplinaridade se mostrou mais eficaz que as outras duas.
${ }^{1} \mathrm{O}$ teste $\mathrm{F}$ (Anova one-way, mais conhecida como Análise de Variância) tem por objetivo testar a igualdade de três ou mais médias de amostras independentes.

${ }^{2}$ Resultado do teste $\mathrm{F}$ aplicado, em que apresentamos os graus de liberdade, o valor do teste e o p-valor. 


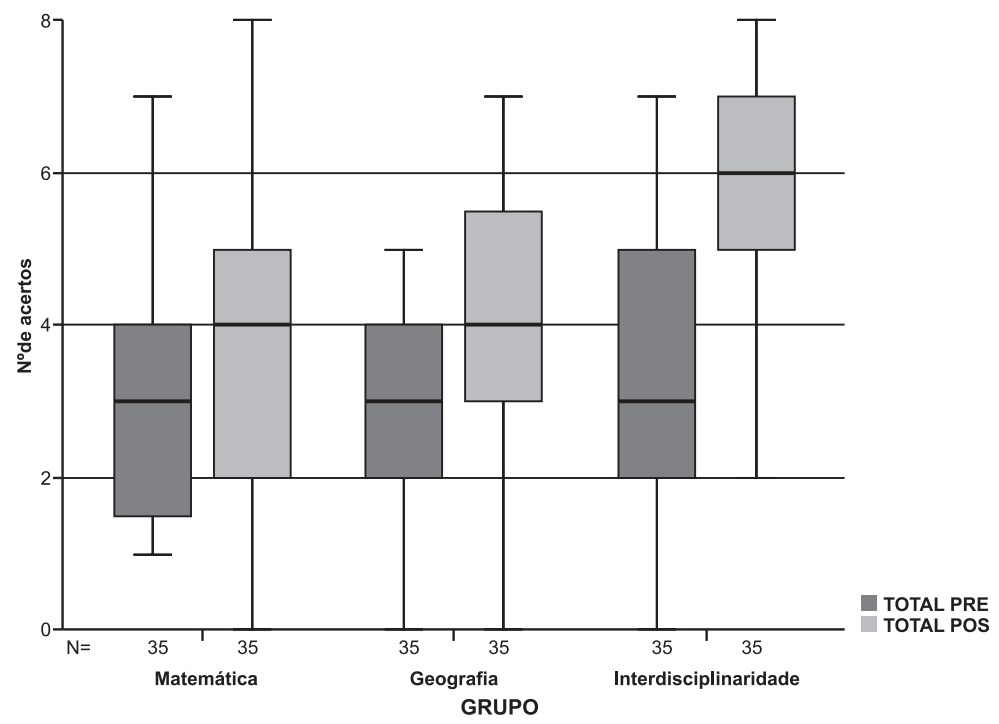

Figura 1 - Resultado dos grupos no pré e pós-teste

O panorama geral dos desempenhos dos grupos, contudo, não permite que identifiquemos onde e como essa diferença a favor do GI se fez presente. Assim, partimos para analisar os resultados no pós-teste segundo os acertos dos grupos em cada questão, procedendo com a comparação entre questões equivalentes por ação requerida (construção ou leitura e interpretação) nos diferentes elementos estatísticos estudados (gráfico e tabela), dando destaque ao Grupo da Interdisciplinaridade (GI), já que foi este que teve o melhor desempenho no instrumento diagnóstico final (pós-teste).

A Figura 2 apresenta os resultados das quatro questões discutidas neste artigo, por grupo.

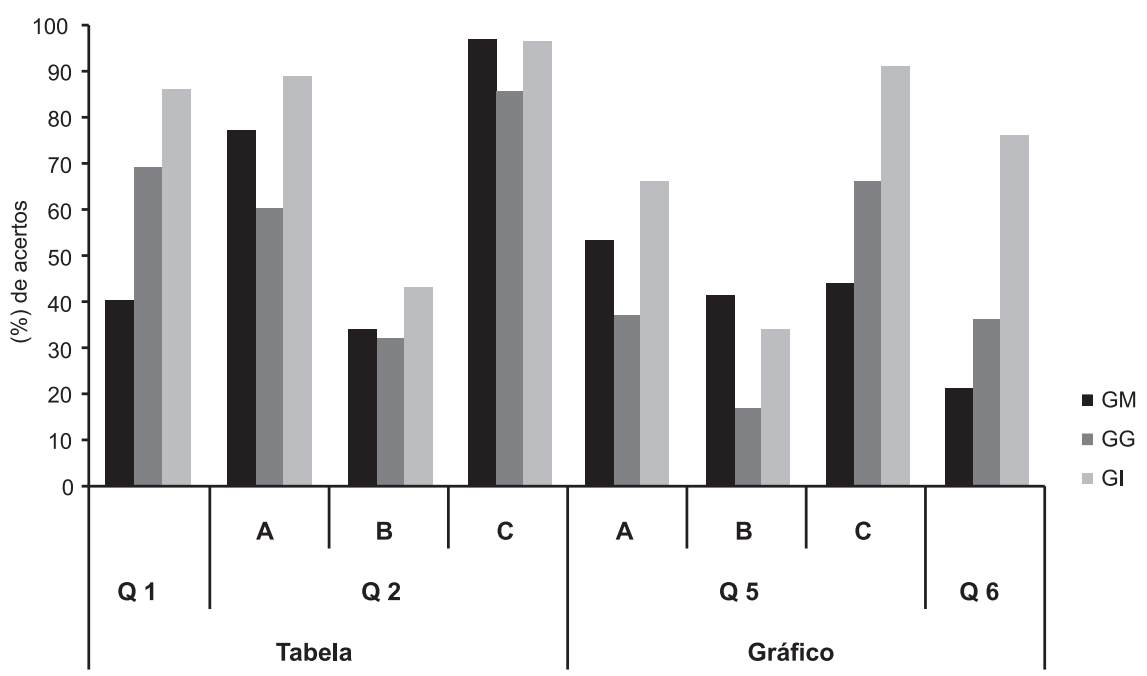

Figura 2 - Porcentagem de acertos das questões por grupo 
Observamos que a média maior de acertos em sete dos oitos itens foi dos alunos do GI, o que confirma que o desempenho desse grupo foi realmente o melhor. Esse resultado nos permite inferir que a intervenção de ensino, quanto às noções de Estatística pautadas nos moldes da interdisciplinaridade, leva os alunos a um sucesso na aquisição do conhecimento, independentemente do elemento estatístico estudado e da ação requerida.

Notamos, ainda, que os três grupos se saíram melhor nas questões cujos dados foram apresentados em tabela (Q1 e Q2) do que naquelas expostas em gráficos, independentemente da ação requerida (construção ou leitura e interpretação). Em relação aos itens 2B e 5B, que dizem respeito à leitura de dados globais (variação), o resultado foi aquém do esperado nos três grupos, o que denota que as intervenções de ensino não foram suficientes para aquisição de tal conhecimento.

Apresentamos a seguir as questões envolvidas nesse estudo com uma análise mais detalhada dos resultados.

A Figura 3 expõe as questões 1 e 6, que envolveram construção (de gráfico e tabela) e abordaram assuntos de Geografia e de Biologia, respectivamente.

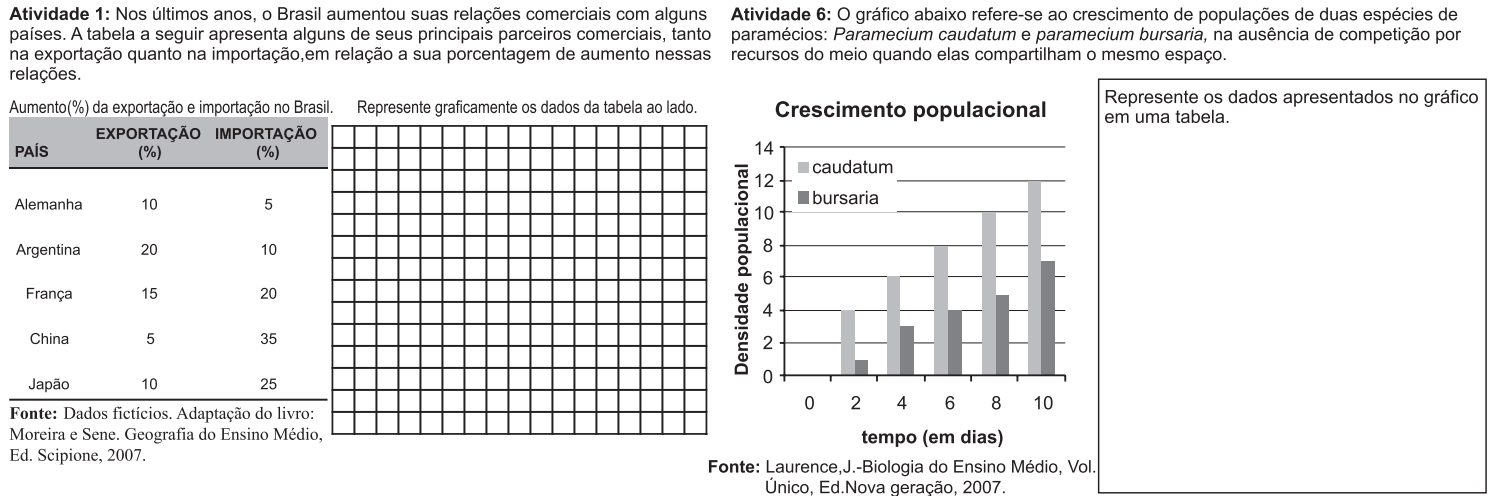

Figura 3 - Questões 1 e 6 dos instrumentos diagnósticos

Quanto aos acertos da questão 1, os resultados apontaram uma diferença estatisticamente significativa no desempenho dos alunos do GG e do GI para o GM $[F(2,98)=8,780 ; p=0,000]$. Encontramos, portanto, nesses dois grupos (GG e GI) um ganho significativo em relação à mudança de registro de tabela para gráfico. Uma possível explicação para esse bom desempenho nos dois grupos foi o fato de que a questão explorou um assunto de Geografia, facilitando o entendimento para os alunos do GG e, no caso do GI, porque a intervenção feita nesse grupo foi de forma interdisciplinar.

Entendendo que a mudança de registro (Duval, 1995) é importante para maior compreensão dos dados estatísticos contidos nas diversas 
representações, inferimos que os alunos do GG e do GI adquiriram maior conhecimento estatístico do que os do GM.

Já na questão 6, o teste F apontou homogeneidade entre o GM e o GG, ficando o GI superiormente separado deles $[F(2,97)=13,795$; $\mathrm{p}=0,000]$. Tais resultados indicaram, novamente, que o GI teve um ganho significativo com a intervenção de ensino, pautada nos moldes da interdisciplinaridade, no que diz respeito à mudança de registro (agora de gráfico para tabela). Em resumo, a maioria dos alunos do GM teve pouco ganho na aprendizagem quanto à mudança de registro, seja de tabela para gráfico ou vice-versa; já a maior parte dos alunos do GG mostrou-se competente para fazer tal mudança apenas em uma direção (tabela para gráfico), e a maioria dos alunos do GI foi capaz de mudar de registro nas duas direções.

Hipotetizamos que o resultado encontrado no GM e no GG se deveu ao fato de existir pouca (ou nenhuma) preocupação, por parte dos professores desses grupos, com a apropriação de um conhecimento construído por meio de uma mudança de registro. De fato, Duval (1995) defende que essa apropriação envolve a mobilização de, pelo menos, dois registros.

Considerando apenas o GI, comparamos os resultados encontrados nas questões 1 e 6, por se tratarem da mudança de registro de tabela para gráfico e vice-versa.

O teste McNemar apontou não existir diferença significativa entre os resultados das questões $(p=0,289)$, indicando que elas eram igualmente fáceis para os alunos, visto que a maioria respondeu corretamente às duas questões que corresponderam à mudança de registro, conforme apresenta o Quadro 1. Uma vez que esse grupo não teve desempenho satisfatório no pré-teste, podemos atribuir esse bom resultado no pós-teste à intervenção de ensino, a qual ocorreu de forma interdisciplinar.

Quadro 1 - Resultado das questões no GI

\begin{tabular}{|l|c|c|c|}
\multirow{2}{*}{\multicolumn{1}{|c|}{ Questão 1 }} & \multicolumn{2}{|c|}{ Questão 6 } & \multirow{2}{*}{ Total } \\
\cline { 1 - 4 } \cline { 1 - 3 } errou (0) & errou (0) & acertou (1) & 4 \\
\hline acertou (1) & 2 & 2 & 30 \\
\hline Total & 6 & 24 & 34 \\
\hline
\end{tabular}

Assim, afirmamos que houve um ganho efetivo do GI quanto à Estatística, pois, conforme defende Duval (2003), a mobilização simultânea de, ao menos, dois registros de representação semiótica constitui uma condição de acesso a sua compreensão.

Analisaremos a seguir as questões 2 e 5, apresentadas na Figura 4, cujos assuntos dizem respeito à Biologia e à Geografia, respectivamente. Em ambas eram solicitadas a leitura e a interpretação dos dados (em tabela e gráfico), distribuídos em três itens. 


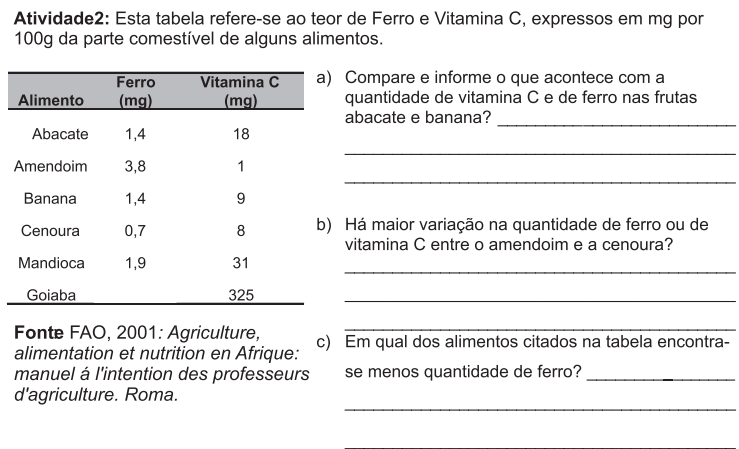

Atividade 5: O gráfico a seguir mostra a evolução da população na Região Norte do Brasil, em relação a sua distribuição percentual da população rural e urbana.

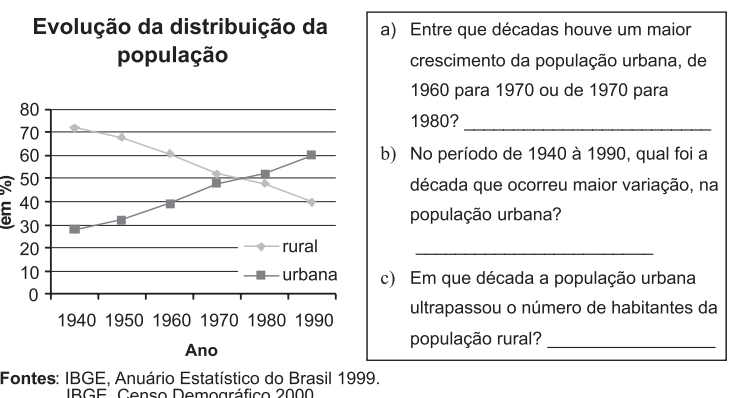

IBGE, Anuário Estatístico do Brasi

Figura 4 - Questões 2 e 5 dos instrumentos diagnósticos

No que se refere ao acerto geral da questão 2, o teste $\mathrm{F}$ apontou que não houve diferença significativa entre os desempenhos do GG e do GM e, ainda, entre o GM e o GI, mas a diferença existe entre o GG e o GI, em favor do GI $[F(2,102)=3,995 ; p=0,021]$. É importante salientar que a questão 2 utiliza o registro de tabela, e isso parece ter favorecido o desempenho do GM. Já com relação ao GI, esse resultado corrobora nossas afirmações anteriores sobre a apropriação dos conhecimentos estatísticos desse grupo após a intervenção de ensino.

Evidenciamos que os percentuais de acerto indicam que os alunos dos três grupos mostraram ter conhecimento necessário para fazer a interpolação entre os dados apresentados em uma tabela (GG = 59\%, GM = 69\% e GI $=76 \%$ ). Segundo os estudos de Wainer (1992), isto significa que os grupos se encontram no nível intermediário de leitura de dados em uma tabela (segundo nível), mas o resultado encontrado com os alunos do GI foi superior aos dos outros dois grupos. Porém, é necessário deixar claro que isto é válido apenas no que tange à comparação dos dados, pois na interpretação da variação destes, embora o GI tenha se saído ligeiramente melhor, os três grupos apresentaram desempenho aquém do necessário para serem classificados no segundo nível identificado por Wainer.

Já na questão 5, os resultados apontaram uma diferença estatisticamente significativa entre o desempenho dos alunos do GM e do GG em relação ao GI, a favor deste último $[F(2,101)=5,902 ; p=0,004]$. De fato, no GG e no GM, a média geral de acertos nessa questão ficou em torno de $50 \%$, enquanto que o GI atingiu 64\%.

Concluímos, portanto, que as médias de acertos do GM e do GG foram pouco satisfatórias, enquanto que os alunos do GI atingiram um índice satisfatório que nos permitiu classificá-los no segundo nível de leitura dos dados em gráficos (Curcio, 1989). Isso significa que o GI atingiu o conhecimento necessário para fazer a interpolação entre os dados apresentados em um gráfico, embora seu desempenho na identificação da variação dos dados tenha ficado a desejar no registro tanto de tabela quanto de gráfico.

O Quadro 2 apresenta os resultados do GI nas questões 2 e 5. Podemos inferir que os alunos desse grupo atingiram um nível de desempenho 
satisfatório quanto à leitura de dados em tabelas e gráficos, ou seja, eles foram capazes de fazer a interpolação entre os dados, não ficando somente na leitura dos dados explícitos, fazendo uso, portanto, de outros conceitos estatísticos.

\section{Quadro 2 - Resultado das questões no GI}

\begin{tabular}{|l|c|c|c|}
\hline \multirow{2}{*}{ Questão 2 } & \multicolumn{2}{|c|}{ Questão 5 } & \multirow{2}{*}{ Total } \\
\cline { 2 - 4 } & errou (0) & acertou (1) & \\
\hline errou (0) & 16 & 9 & 25 \\
\hline acertou (1) & 22 & 58 & 80 \\
\hline Total & $\mathbf{3 8}$ & $\mathbf{6 7}$ & $\mathbf{1 0 5}^{*}$ \\
\hline
\end{tabular}

*Total correspondente a 35 alunos respondendo 3 itens nas questões.

Um fato importante que devemos considerar é a dificuldade que os alunos encontraram ao realizar a atividade que requer a leitura de dados em gráficos. Se compararmos as médias de acertos da questão 2 com a 5, que requer o mesmo tipo de ação nos elementos estatísticos, podemos inferir que os alunos dos três grupos têm maior facilidade em fazer a leitura e a interpretação de dados quando são apresentados em tabelas. O mesmo ocorreu na mudança de registro, em que encontramos melhor resultado quando a leitura dos dados foi realizada numa tabela (questão 1) para a construção de um gráfico do que ao contrário.

\section{Considerações finais}

Após a análise dos resultados dos três grupos, sentimo-nos confortáveis para fazermos algumas afirmações conclusivas. Primeiramente, no que diz respeito à conversão de registros, os alunos do Grupo da Interdisciplinaridade foram os que apresentaram melhor desempenho no assunto estudado, segundo os princípios da teoria de Duval (1995), pois tiveram um índice de acertos satisfatório. Assim, os alunos desse grupo, ao se depararem com uma atividade na qual lhes era solicitado transitar entre mudança de registro de representação, foram os que se saíram melhor entre os três grupos pesquisados. Desse ponto de vista, podemos considerar que eles se apropriaram dos conhecimentos elementares da Estatística, uma vez que sempre que requisitados conseguiram mobilizar os dois registros de representação. O mesmo já não se pode afirmar sobre os alunos do GG, pois só conseguiram tal mobilização em uma direção (da tabela para o gráfico), e muito menos do GM, cuja mobilização não aconteceu em nenhuma das direções.

A segunda conclusão possível diz respeito à leitura e à interpretação dos dados em tabelas e gráficos, segundo os estudos realizados por Wainer (1992) e Curcio (1989). Novamente, os alunos do GI foram os que apresentaram melhor resultado diante de ambas as representações. 
Especificamente no trabalho com tabelas, constatamos que, embora o GI tenha se saído melhor do que os outros dois, todos eles se encontram no segundo nível de leitura dos dados. Já ao trabalhar com gráficos, apenas o GI atinge esse nível. E o mais sério é que a maioria dos alunos do GM não chega a atingir nem o primeiro nível proposto nos estudos de Curcio.

Por fim, a terceira conclusão refere-se ao desempenho dos três grupos quanto à capacidade de identificar a variação entre os dados, seja em tabela ou em gráfico. De fato, nenhum dos grupos teve mais do que 39\% dos alunos capazes de interpretar corretamente as variações nas duas representações (tabela e gráfico), sendo que isso é mais preocupante no GG, visto que tal capacidade se restringe a menos de um quarto dos alunos.

Nossa conclusão principal é de que o ensino de Estatística pautado nos moldes da interdisciplinaridade é mais eficaz para a aprendizagem de seus conceitos elementares. Explicamos tal conclusão defendendo a ideia de que esta interdisciplinaridade provoca interesse dos alunos pelos assuntos estudados em outras disciplinas escolares no mesmo momento em que esses assuntos facilitam na compreensão dos conceitos estatísticos. É, portanto, uma aprendizagem retroalimentada entre os conceitos advindos de outras disciplinas e os conceitos estatísticos.

Por fim, notamos ao longo da intervenção de ensino do GI que os interesses, motivações e curiosidades dos alunos, advindos da exploração de situações escolares e extraescolares, trouxeram como consequência uma conscientização da importância de se fazer corretamente uma leitura dos dados apresentados em gráficos e tabelas. Eles passaram a entender que para poder inferir suas opiniões sobre o assunto era necessário baseá-las na compreensão estatística dos dados. O fruto de tal conscientização foi o desempenho satisfatório que este grupo apresentou no pós-teste, sendo inclusive significativamente superior aos dos demais grupos.

\section{Referências bibliográficas}

BATANERO, Carmen (Ed.). Training researchers in the use of statistics. Granada: International Association for Statistical Education e International Statistical Institute, 2001.

BRASIL. Ministério da Educação e do Desporto/Secretaria de Educação Fundamental. Parâmetros Curriculares Nacionais: Matemática. Brasília: MEC/SEF, 1998.

. Parâmetros Curriculares Nacionais: Matemática Ensino Médio.

Brasília: MEC/SEF, 1999.

CURCIO, Frances R. Developing graph conprehension. Virginia: National

Council of Teachers of Mathematics. ISBN 0-87353-277-5, 1989. 
DUVAL, Raymond. Sémiosis et pensée humaine: registres sémiotiques et apprentissages intellectuels. Berna: Peter Lang. 1995.

. Registros de representações semióticas e funcionamento cognitivo da compreensão em Matemática. In: MACHADO, Silvia Dias Alcântara (Org.). Aprendizagem em Matemática: registros de representação semiótica. 4. ed. Campinas: Papirus, 2003. p. 11-33.

GAL, Iddo. Adult's statistical literacy: meanings, components, responsabilities. International Statistical Review, v. 70, n. 1, p. 1-25, 2002.

KLEIN, Julie Thompson. Ensino interdisciplinar: didática e teoria. In: FAZENDA, Ivani (Org.) Didática e interdisciplinaridade. 12. ed. Campinas: Papirus, 2007. p. 109-132.

LOPES, Celi Aparecida Espasandin. Literacia estatística e o Inaf 2002. In: FONSECA, Maria da Conceição Ferreira Reis (Org.). Letramento no Brasil - habilidades matemáticas: reflexões a partir do Inaf 2002. São Paulo: Global-Ação Educativa Assessoria, Pesquisa e Informação/ Instituto Paulo Montenegro, 2004b, p. 187-197. Disponível em: <www. iberomat.uji.es/carpeta/posters/148_celi_espasandin_lopes.doc $>$. Acesso em: 31 ago. 2008.

. O ensino de probabilidade e estatística na escola básica nas dimensões do currículo e da prática pedagógica. XVI Simpósio Iberoamericano de Enseñanza Matemática. Carpeta/posters/148. Castellón, España, 2004a.

NOVAES, Diva Valério; COUTINHO, Cileda de Queiroz e Silva. Estatística para educação profissional. São Paulo: RBB, 2008.

PAGAN, Maria Adriana. A interdisciplinaridade como proposta pedagógica para o ensino de Estatística na educação básica. 2010. Dissertação (Mestrado em Educação Matemática) - Pontifícia Universidade Católica de São Paulo (PUC-SP), São Paulo.

SÃO PAULO. Secretaria do Estado da Educação. Coordenadoria de Estudos e Normas Pedagógicas. Proposta curricular do Estado de São Paulo: Matemática. Coord. Maria Inês Fini. São Paulo, 2008.

WAINER, Howard. Understanding graphs and tables. Educational Researcher, v. 21, n. 1, p. 14-23, 1992. Disponível em: <http://edr.sagepub.com/cgi/content/abstract/21/1/14>. Acesso em: 26 jan. 2009. 
Adriana Pagan, mestre em Educação Matemática pela Pontifícia Universidade Católica de São Paulo (PUC-SP), é servidora pública da Secretaria Estadual de Educação (SEE) e atua como professora titular de cargo em uma escola estadual em São Paulo-SP.

dripagan@yahoo.com.br

Sandra Magina, doutora em Educação Matemática pela Universidade de Londres, com pós-doutorado na Universidade de Lisboa, Portugal, é professora titular da Pontifícia Universidade Católica de São Paulo (PUC-SP) e membro do programa de pós-graduação em Educação Matemática da referida Universidade.

sandra@pucsp.br

Recebido em 25 de novembro de 2010.

Aprovado em 29 de setembro de 2011. 